\title{
$\begin{array}{lllllllll}\text { I } & N & S & T & \text { I } & \text { T } & \text { U } & \text { T } & \text { E }\end{array}$
}

\section{Profile of New Hampshire's Foreign-born Population}

\author{
ROSS GITTELL AND TIMOTHY LORD
}

\section{O V E R V I E W}

$\mathbf{N}$ ew Hampshire, like the rest of the nation, is experiencing an increase in the numbers and diversity of its foreign-born population. ${ }^{1}$ The state's foreignborn population has experienced significant changes recently that are different from most other states.

\section{HIGHLIGHTS OF THE REPORT ${ }^{2}$}

- The percentage of the population that is foreign born in New Hampshire was above the national average in the first half of the 20th century and now it is significantly below the national average.

- In the early 2000 s_-from a relatively low base-the state's percentage of foreignborn population has been increasing faster than all but six other states.

- Immigrants to New Hampshire come from a wider range of places than is true elsewhere.

- New Hampshire's foreign-born population has higher levels of educational attainment and income than the national average.

- New Hampshire's foreign-born population is geographically concentrated in Hillsborough County and Manchester.

- In the 1990s, New Hampshire had a lower foreign-born growth rate than the national average, but that is changing in the 21 st century.

\section{New Hampshire History of Foreign-born} Population: Percentage swings from above to below national averages

At the turn of the 20th century, New Hampshire had over 88,000 foreign-born persons, over 15,000 more than it has today. In 1900, the state's concentration of foreign born (21 percent) was higher than the national average percentage and more than three times the current percentage of 6 percent in the state. In 1900, New Hampshire ranked 15th of all states in percentage of the foreign-born population. Currently, New Hampshire ranks 26th of the 50 states.

The number of foreign born living in New Hampshire and New England peaked around 1920 before a number of restrictive immigration policies were put in place nation-wide. With the limits on immigration from many countries but not from Canada, in 1950 New Hampshire had the 6th highest foreign born percent of the population in the nation (see Table 1).

Table 1: 1950 Foreign-born Population Percentage New England State Rankings

\begin{tabular}{|c|c|c|c|c|}
\hline & State & $\begin{array}{c}\text { 1950 Foreign-born } \\
\text { Population Percent }\end{array}$ & $\begin{array}{c}\text { 1950 Foreign-born } \\
\text { Population }\end{array}$ & $\begin{array}{c}\text { 1950 Total } \\
\text { Population }\end{array}$ \\
\hline 2 & Massachusetts & 15.4 & 721,230 & $4,672,020$ \\
\hline 3 & Connecticut & 14.8 & 296,040 & $1,996,050$ \\
\hline 4 & Rhode Island & 14.4 & 113,395 & 788,170 \\
\hline 6 & New Hampshire & 10.9 & 57,475 & 529,330 \\
\hline 11 & Maine & 8.2 & 74,475 & 908,850 \\
\hline 13 & Vermont & 7.6 & 28,400 & 375,335 \\
\hline & New England & $\mathbf{1 3 . 9}$ & $\mathbf{1 , 2 9 1 , 0 1 5}$ & $\mathbf{9 , 2 6 9 , 7 5 5}$ \\
\hline & United States & $\mathbf{6 . 9}$ & $\mathbf{1 0 , 3 4 7 , 3 9 5}$ & $\mathbf{1 5 0 , 2 1 6 , 1 1 0}$ \\
\hline
\end{tabular}

Source: U.S. Census Bureau, Population Division. 1950 Decennial Census 
As in other states, the national immigration policies resulted in a decline in New Hampshire's foreign-born population and it reached its lowest point in the 1970s. With the changes to national immigration policies, New Hampshire's foreign-born population has increased since the 1970 s, but slowly compared to the national average until recently.

\section{New Hampshire's Current Foreign-born Population}

In 2005, New Hampshire had approximately 72,000 foreign-born persons according to Census figures. This represents about 6 percent of the state's total population. The state now has only one-half the national (12.4) average percent of foreign born in the population, see table below. This relatively low percentage of the population who are foreign born in New Hampshire represents a change from historical patterns.

It is very difficult to determine the number of undocumented immigrants in the population. Estimates from the Pew Hispanic Center indicate that the undocumented immigrant population in the state is relatively small both in numbers and as a percent of the total population. According to Pew Hispanic Center estimates, New Hampshire had less than 10,000 undocumented immigrants in 2000 and anywhere from 10,000 to 30,000 in 2005 . The large range of these numbers reiterates how challenging these estimates can be, however these figures suggest that from a low base the undocumented immigrant population in the state may be growing.
Figure 1: Percent of Foreign-born Population, 1900, 1950 AND 2000

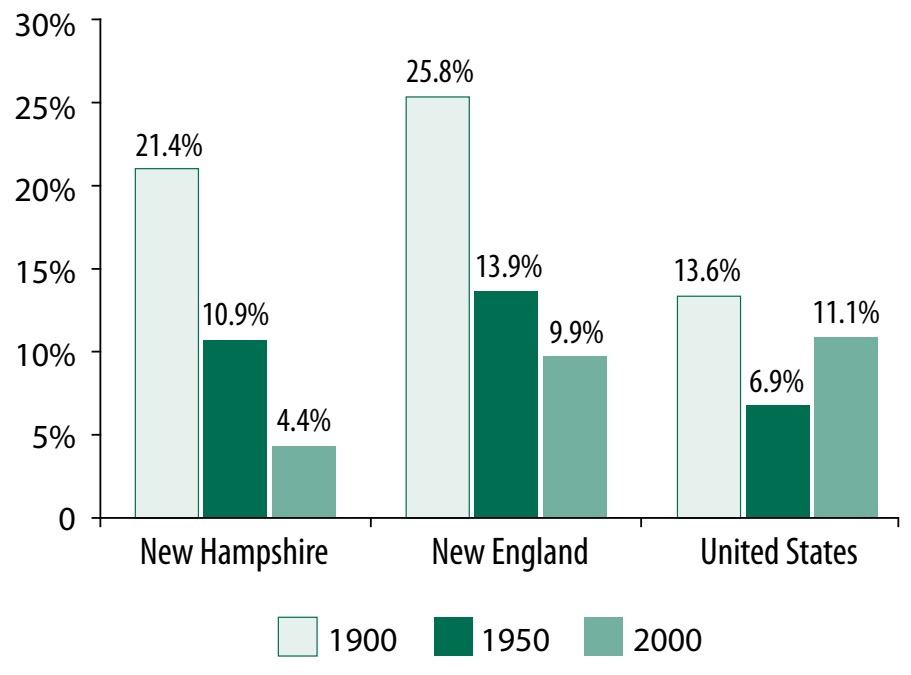

Source: U.S. Census Bureau, Population Division. Decennial Census

\section{Figure 2: Foreign Born Population Average Annual Percentage Change}

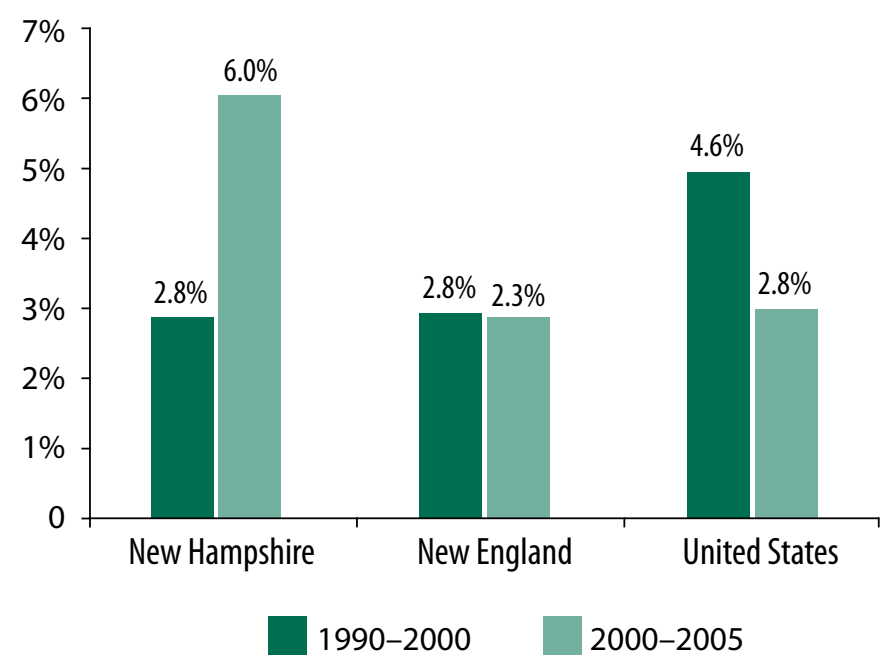

Source: U.S. Census Bureau, Population Division. 1990 and 2000 Decennial Census and 2005 American Community Survey 
Slow Growth in Foreign-born Population in the 1990s Compared to the Nation Followed by Relatively Rapid Growth in Early 2000s

The 1990s were a decade in New Hampshire of particularly slow growth in the foreign-born population compared to other regions of the country. New Hampshire's foreign-born population numbers grew 32 percent, or about one-half the U.S. average growth of 58 percent and significantly lower than the fastest growing states in foreign population, including North Carolina and Georgia (which both had their foreign-born populations grow by over 230 percent).

New Hampshire's growth in the foreign-born population has increased in the early 2000s, when the state ranked 7 th in the United States in growth. After growing at an average rate of 2.8 percent per year in the $1990 \mathrm{~s}$, New Hampshire's foreign-born population growth has doubled between 2000 and 2005, to 6 percent per year.

\section{Different Composition of Foreign Born in New Hampshire Compared to U.S. Average}

A significant portion of the nation's foreign-born population increases were Mexican immigrants. New Hampshire's foreign-born population is more diverse with respect to countries of origin than the national average. The top five countries of origin of the Census reported foreignborn in New Hampshire are Canada (17 percent), India (6 percent), Vietnam (5 percent), Germany (4 percent), and China (4 percent). The Census data does not account for so-called "hidden populations" of persons who don't respond to Census inquires. These are estimated to be disproportionately people of color and from poorer countries, such as immigrants to New Hampshire from Mexico and African nations.

The composition and character of the foreign-born population in New Hampshire is very different than the U.S. average, with a much lower percentage of Mexican and much higher percentage of Canadian immigrants. Nationally over 30 percent of all documented foreign-born persons are from Mexico. This contrasts to New Hampshire with Mexican immigrants accounting for just 2 percent of the state's foreign-born population.

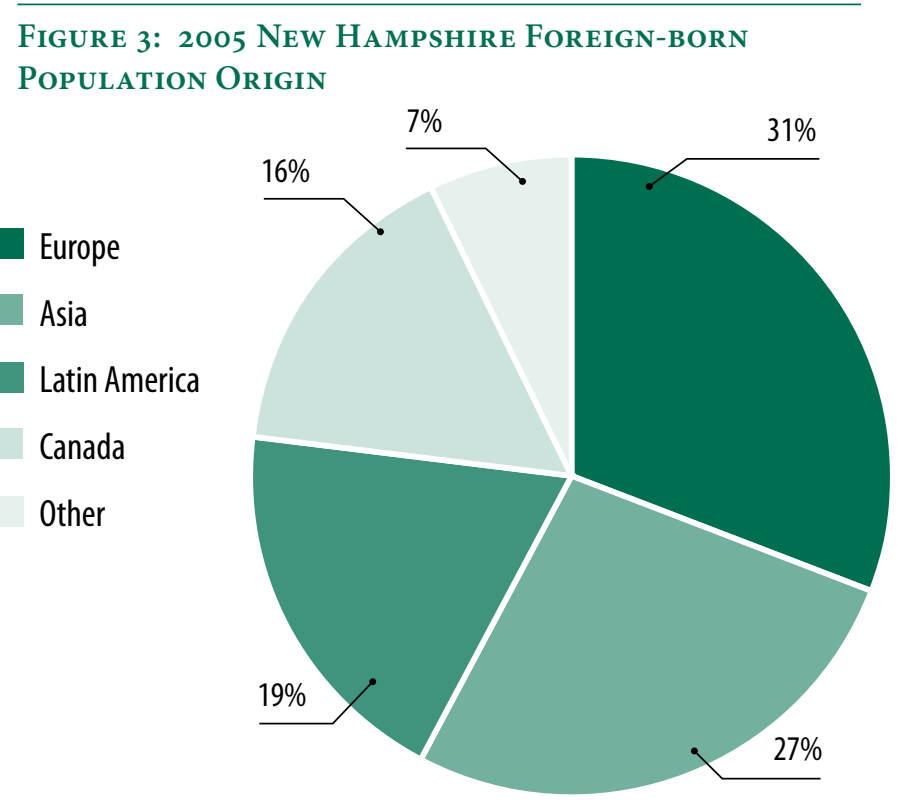

Source: U.S. Census Bureau, Population Division. 2005 American Community Survey

Figure 4: 2005 United States Foreign-bORN Population Origin

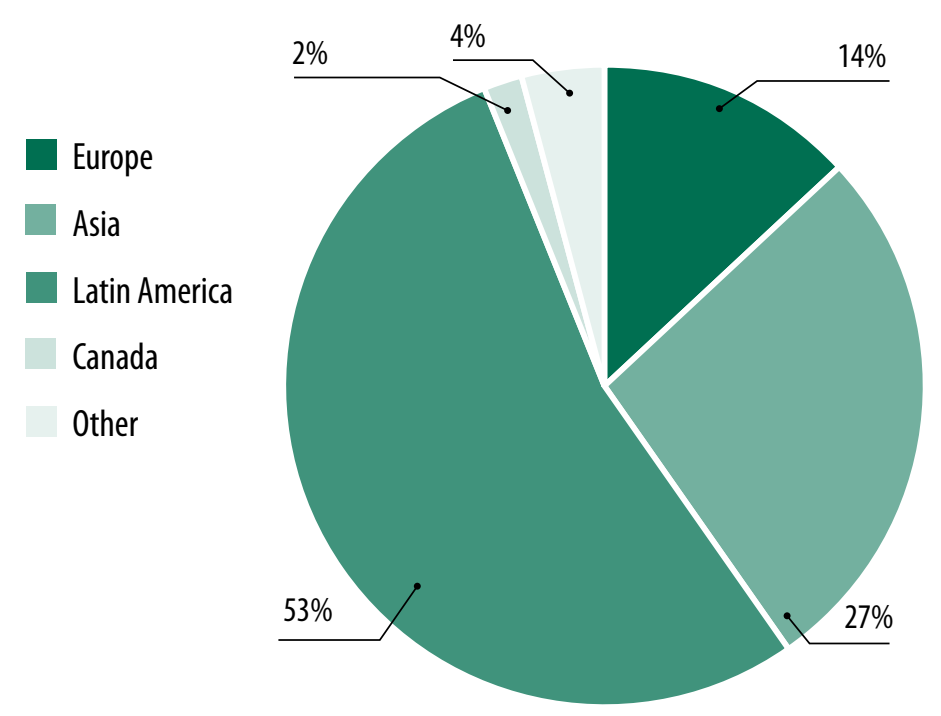

Source: US Census Bureau, Population Division. 2005 American Community Survey 
There is increasing diversity of the foreign-born population in New Hampshire. The fastest growing foreign-born countries of origin to New Hampshire are Vietnam, India, Brazil, and Russia. (See table below.) There are also increasing numbers of foreign-born in New Hampshire from Jamaica, China, Portugal, France, and Israel. At the same time there has been a decline in the numbers from Canada and the United Kingdom, primarily from the migrationout or death of immigrants from these countries who had previously settled in New Hampshire.

It is notable that New Hampshire's foreign-born population has relatively

It is notable that New Hampshire's foreign-born population has relatively high educational

\section{achievement and} high income. high educational achievement and high income. This population is also older than the U.S. average. Comparatively, New Hampshire also has relatively low percentages of children with foreignborn parents, foreign-born children living in poverty, and immigrant children with difficulty speaking English.

New Hampshire currently ranks first among the 50 states in the percentage of foreign-born adults (25 and over) with a

4-year college degree, at 24 percent compared to the U.S. average of 16 percent. The foreign born in New Hampshire also have 30 percent higher income than the national foreign-born average, and have an average age 2.4 years older than in the U.S. generally.

Close to one in ten (9 percent) of all children in New Hampshire are in immigrant families with at least one foreign-born parent. This is low, compared to 21 percent of all children in the nation who have at least one foreignborn parent. Eleven percent of children in immigrant families in New Hampshire live in poverty, compared to 22 percent on average nationally in the United States. This eleven percent figure for immigrant children in poverty in New Hampshire is very close to the relatively low 9 percent of all New Hampshire children who live in poverty.

\section{Geographic Concentration in New Hampshire of Foreign Born}

As in the region and nation, there is significant geographic concentration of the foreign-born population in New Hampshire. The state's foreign-born population is concentrated in one county, Hillsborough County, with over 38,000 foreignborn persons, representing over 50 percent of the state's reported foreign-born population (compared to less than one-third of the state's total population). Hillsborough has a reported foreign-born population of $9.7 \%$ of total population, making it the only county in New Hampshire with a foreign-born percentage of the total population above the state-wide average of 5.7 percent. The county with the second highest foreign-born population, Rockingham, has less than one half the foreign-born population of Hillsborough.

The concentration of the state's foreign-born population in Hillsborough County has been increasing. The County represented 70 percent of the recent (2000 to 2005) increase in the foreign-born population in the state. The foreignborn increase in the county contrasts to (just) 5 percent of net internal domestic migration (which includes some foreign born new residents) into the state to Hillsborough County over a similar time period.

While foreign-born population growth in the state is concentrated in Hillsborough, the foreign-born population has been growing at a relatively high rate-over 20 percent in the 1990s and/or 2000 to 2005 (where data is available) - in six of the 10 New Hampshire counties. ${ }^{3}$ The exceptions are Coos County which has been experiencing a decline in foreign born, and Cheshire and Sullivan which have had slow growth in the numbers of foreign born.

Hillsborough County is one of only a small number of areas in New England with relatively high concentrations of foreign-born population. Only 8 of 67 New England counties have a 2005 foreign-born population percentage above the regional average. This currently does not include Hillsborough County, but probably soon will.

The county had the 2 nd fastest county growth in the entire New England region, a nearly 50 percent increase in the last 5 years. In Hillsborough over 50 percent of the foreign born are from Asia and Latin America. 
Figure 5: Change in Foreign-born Population in New Hampshire by Country of Origin, 2000-2005

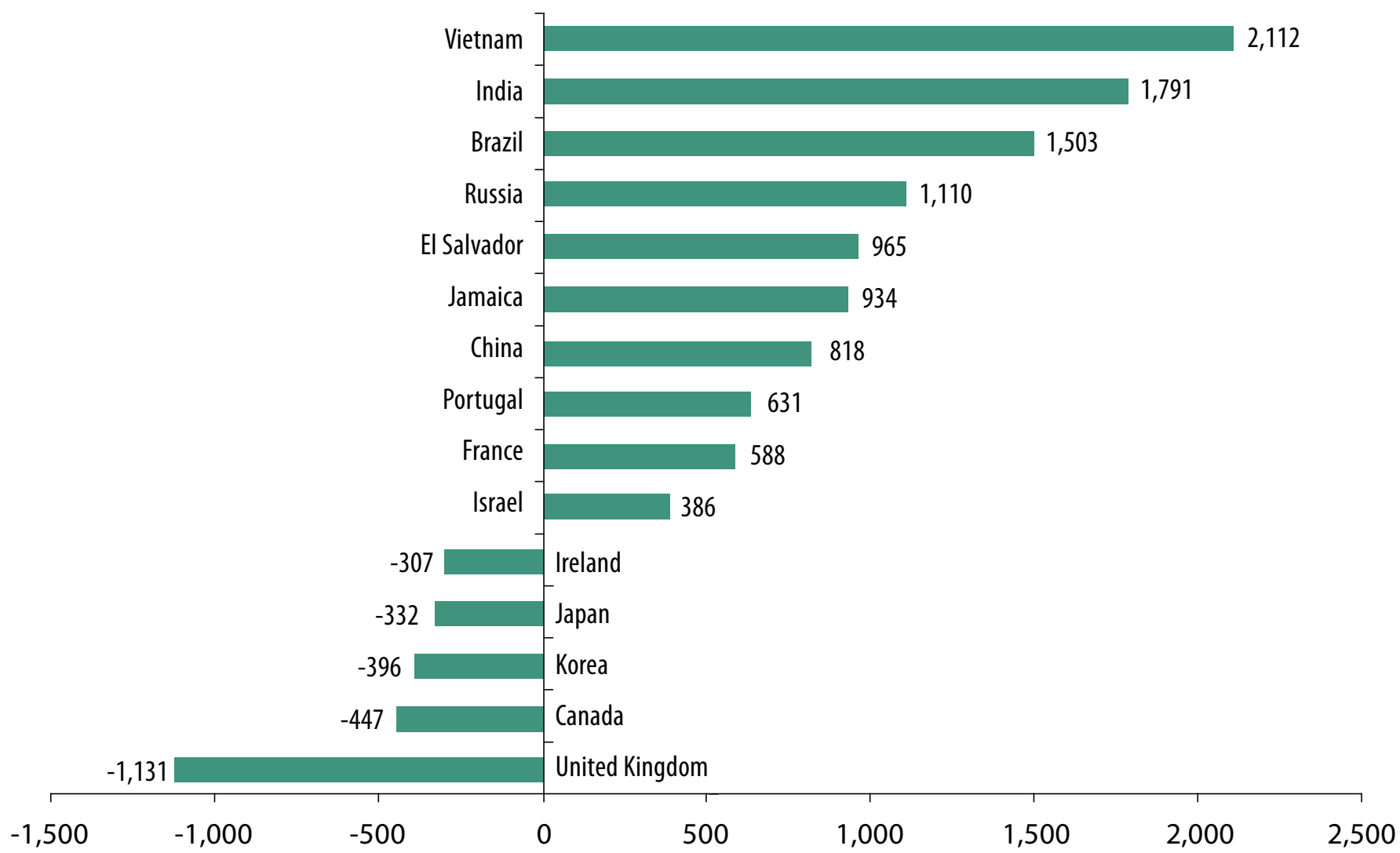

Source: U.S. Census Bureau, Population Division. 2000 Decennial Census and 2005 American Community Survey 


\section{Refugee Resettlement in New Hampshire}

Roughly 6 percent of New Hampshire's foreign-born population are refugees-persons who have been forced to flee their home countries due to a well-founded fear of persecution for reasons of race, religion, nationality, political opinion, or membership in a particular social group. Refugees are placed at the discretion of the U.S. State Department in collaboration with two local resettlement agencies: Lutheran Social Services of New Hampshire and the International Institute of New Hampshire; those refugees who are brought to New Hampshire have not had the ability to choose their initial resettlement location. Once resettled, however, refugees are as free to relocate as any other legal residents. Since there thus can be both in-migration and out-migration of refugees, precise total New Hampshire refugee population figures are not readily available.

Data is nonetheless available as to exactly how many refugees have been initially placed in New Hampshire. ${ }^{4}$ Between 1997 and 2006, there were 4,063 refugees settled in New Hampshire. About three-fourths of the refugees placed in New Hampshire have been resettled in the city of Manchester, with over 5,000 refugees resettled there since resettlement started in New Hampshire in 1980. In recent years, in addition to Manchester, Concord, Laconia, and, to a lesser extent, Nashua and Franklin have also been primary New Hampshire resettlement locations. New Hampshire typically resettles about 250-300 refugees annually. A total of 257 refugees were resettled in New Hampshire in 2007.

New Hampshire refugees have come from more than 30 different countries of origin. Over half of the refugees resettled in New Hampshire in the past decade have come from Europe $(2,202)$, with three-fourths of these European refugees from Bosnia $(1,656)$. There have also been significant numbers of refugees from Africa $(1,512)$ including from the Sudan (520), Somalia (453) and Liberia (243). Other significant numbers include Meshketian Turks (159) as well as refugees from Croatia (168), Vietnam (144), Ukraine (96) Afghanistan (92), Iraq (86), Rwanda (65) and Nigeria (59). Over the next few years increasing numbers of Bhutanese and Iraqi refugees are expected in the nation and in New Hampshire.

The New Hampshire Refugee Resettlement Program reports that in 2007, New Hampshire refugees achieved an $84 \%$ job placement rate within four and a half months of arrival in this country.

Figure 6: Hillsborough County, NH 2000-2006 Change in Foreign-born Population by Country of Origin

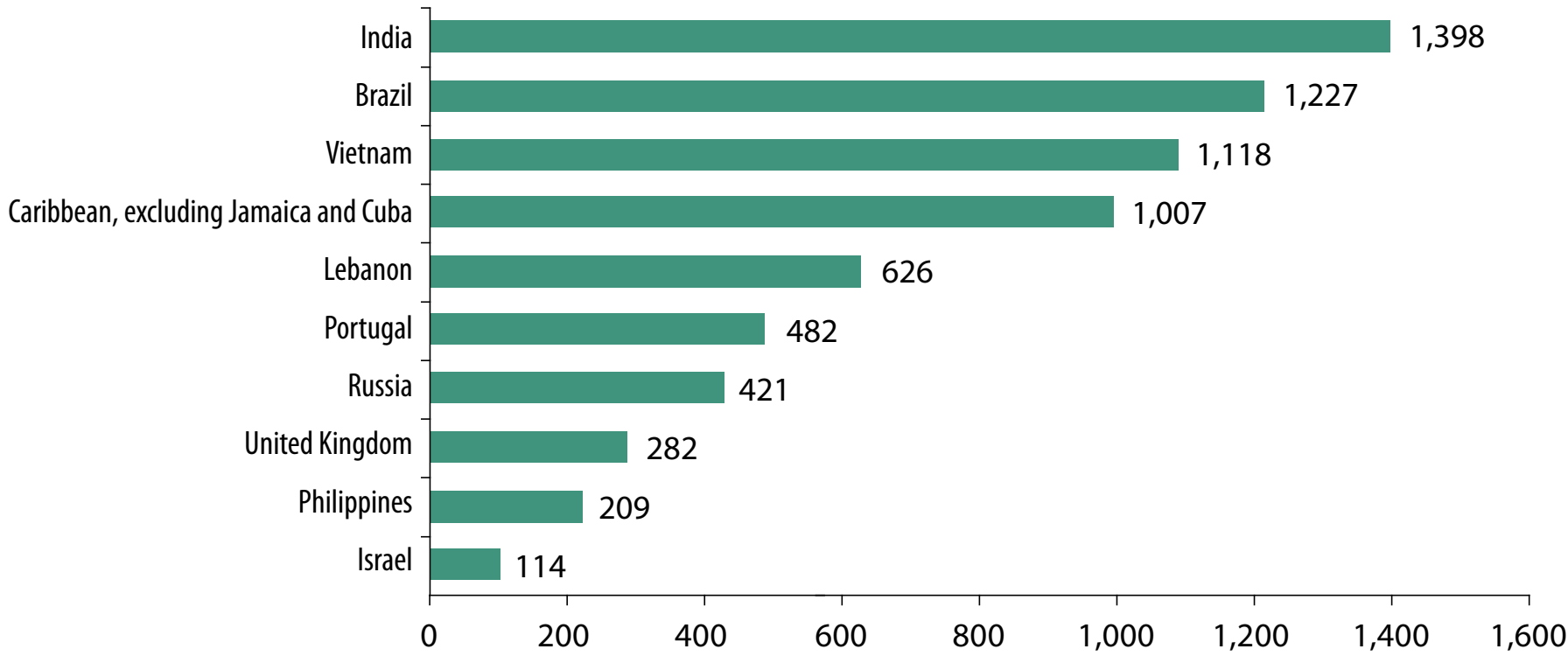




\section{Conclusion}

New Hampshire has a long history of immigration and foreign-born population. Currently, the state's foreign-born population is growing faster on a percentage change basis then the national average. However, New Hampshire still has a significantly lower percentage of residents who are foreign born than the national average and significantly lower foreign born percentage than at the turn of the previous century. The region's foreign-born population is different than the national composition, and is, on average, more highly educated than in any other state. In a similar manner that highly educated domestic in-migrants helped to transform the New Hampshire economy and improved the state's competitive economic position in the last decades of the 20th century, foreign immigrants will be able to contribute to the 21st century economy in New Hampshire. The foreign born represent an increasing proportion of the state's population and will have a significant influence on the state's economic, social, and cultural future.

\section{ENDNOTES}

1 The foreign-born population consists of legal immigrants who are citizens and non-citizens, undocumented immigrants, and temporary residents such as students and workers on business visas.

2 All the data and tables report U.S. Census data from the Decennial 1950, 1980, 1990 and 2000 Censuses and from the 2005 American Community Survey (ACS) estimates. The ACS data is subject to revisions and re-estimates. In some of the smaller New England states and counties the estimates of foreign-born can be subject to significant revision.

3 U.S. Census data on the foreign born in 2005 are just available for the largest counties in New Hampshire. Counties with an asterisk denote 2000 data.

4 Source of refugee statistics: New Hampshire Office of Energy and Planning, New Hampshire Refugee Program. 


\section{AUTHORS}

Ross Gittell is a Senior Fellow at the Carsey Institute and the James R. Carter Professor of Management at the Whittemore School of Business and Economics.

(ross.gittell@unh.edu)

Tімотну LoRD is a graduate student at the University of New Hampshire Whittemore School of Business and Economics. (tlord@cisunix.unh.edu)

\section{CARSEY I N S T I T U T E}

Building knowledge for families and communities

The Carsey Institute at the University of New Hampshire conducts independent, interdisciplinary research and communicates its findings to policy makers, practitioners and the general public.

Huddleston Hall

73 Main Street

Durham, NH 03824

(603) 862-2821

www.carseyinstitute.unh.edu 